\title{
PARÂMETROS CLÍNICOS E HEMATOLÓGICOS DE REPRODUTORES CAPRINOS INFECTADOS NATURALMENTE PELO VÍRUS DA ARTRITE ENCEFALITE CAPRINA DURANTE A TRANSIÇÃO DA ESTAÇÃO SECA PARA CHUVOSA NO CEARÁ
}

\author{
N.R.O. Paula ${ }^{1 *}$, A. Andrioli' ${ }^{2}$, J.F.S. Cardoso ${ }^{3 * *}$, F.M.L. Sousa ${ }^{4}$, \\ K.C. de Souza ${ }^{4}$, R.R. Pinheiro' ${ }^{2}$, F.S.F. Alves ${ }^{2}$, M.F.S. Teixeira ${ }^{1}$
}

1Universidade Estadual do Ceará, Laboratório de Virologia, Av. Paranjana,1700, Campus doItaperi, CEP60740000, Fortaleza, CE, Brasil. E-mail: neyromulo@hotmail.com

\section{RESUMO}

\begin{abstract}
A artrite encefalite caprina (CAE) é uma doença infecciosa específica dos caprinos. Geralmente apresenta-se de forma crônica, caracterizando-se por um longo período de incubação e uma evolução clínica lenta e progressiva. O objetivo deste trabalho foi avaliar os parâmetros clínicos e hematológicos de reprodutores caprinos naturalmente infectados pelo vírus da CAE, bem como verificar a influência da transição das estações seca e chuvosa no Ceará nestes parâmetros. O trabalho foi conduzido na Empresa Brasileira de Pesquisa Agropecuária, Embrapa Caprinos, no Município de Sobral, CE. Foram utilizados oito reprodutores caprinos positivos para CAE, mantidos em um sistema semi-intensivo de criação, submetidos a exames clínicos quinzenais e a hemograma completo mensal, durante o período de setembro de 2006 a fevereiro de 2007. Os dados foram expressos na forma de média e analisados pelo software Staview a $5 \%$ de probabilidade. Observou-se um aumento significativo da freqüência cardíaca durante a estação chuvosa $(90,09 \pm 16,21 \mathrm{bpm})$. Oíndice articular clínico superior a sete, considerado indicativo de um quadro clínico de artrite, foi verificado em três animais durante todo o experimento, todavia a estação climática não interferiu neste parâmetro. Foi observado um aumento significativo na contagem absoluta de eosinófilos $(90,09 \pm 16,21 / \mu \mathrm{L})$ e monócitos $(100,91 \pm 21,12 / \mu \mathrm{L})$ durante a estação chuvosa. Conclui-se que a estação climática não altera os parâmetros físicos de reprodutores caprinos infectados pelo CAEV explorados na região norte do Estado do Ceará. Todavia, a estação chuvosa propicia condições climáticas e ambientais que alteram a contagem de monócitos e eosinófilos desses reprodutores.
\end{abstract}

PALAVRAS-CHAVE: Caprino, CAEV, parâmetros clínicos e hematológicos.

\section{ABSTRACT}

CLINICALANDHEMATOLOGICPARAMETERSOFCAPRINEREPRODUCERSNATURALLY INFECTED BY CAPRINE ARTHRITISENCEPHALITIS VIRUSDURING THETRANSITION FROM THE DRY TO THE RAINY SEASON IN THE STATE OF CEARÁ, BRAZIL. Caprine arthritis encephalitis (CAE) is a specific infectious disease of caprines. It usually leads to a chronic disease, being characterized by a long incubation period and a slow and progressive clinical evolution. The aim of this work was to evaluate the clinical and hematologic parameters of bucks naturally infected by the CAE virus, as well to verify the influence of the transition from the dry to rainy season in the state of Ceará, Brazil, on these parameters. The work was carried out at the Brazilian Agricultural Research Corporation - Goats in Sobral, state of Ceará. A total of 8 bucks positive for CAE were used, maintained in a semi-intensive raising system and submitted to biweekly clinical exams and complete blood count monthly, from September 2006 to February 2007. The data were expressed as means and analyzed using the software Staview with $5 \%$ of probability. A significant increase of the heart rate was observed during the rainy station $(90.09 \pm 16.21 \mathrm{bpm})$.

\footnotetext{
${ }^{2}$ Embrapa Caprinos, Sobral, CE, Brasil.

${ }^{3}$ RENORBIO, Fortaleza, CE, Brasil.

${ }^{4}$ Universidade Vale do Acaraú, Sobral, CE, Brasil.

*Doutorando do Programa de Pós-graduação em Ciências Veterinárias, PPGCV, UECE.

**Doutoranda do Programa de Pós-graduação em Biotecnologia - RENORBIO.
} 


\begin{abstract}
An articular clinical index superior to 7, considered as a clinical indication of arthritis, was verified in 3 animals during the experiment, although the climatic season did not influence this parameter. A significant increase was observed in the absolute count of eosinophiles $(90.09 \pm 16.21 / \mu \mathrm{L})$ and monocytes $(100.91 \pm 21.12 / \mu \mathrm{L})$ during the rainy season. We conclude that the climatic season did not alter the physical parameters of the CAEV-infected bucks studied in this experiment in the north of the state of Ceará, Brazil. However, the rainy station provides climatic and environmental conditions that alter the monocyte and eosinophile count of these bucks.
\end{abstract}

KEY WORDS: Caprine, CAEV, clinical and hematologic parameters.

\section{INTRODUÇÃO}

A síndrome artrite-encefalitecaprina (CAE)éuma enfermidade multissistêmica crônica de caprinos, causada por um retrovírus não-oncogênico (CAEV), caracterizando-se por um longo período de incubação e evolução clínica longa e progressiva. Os animais infectados passam a ser portadores permanentes do vírus. A CAE pode manifestar-se por meio de cinco quadros clínicos principais: poliartrite crônica, mamite, encefalite em animais jovens, pneumonia e emagrecimento crônico (FrANKE, 1998).

O CAEV pertence à famíliaRetroviridae, apresenta em cada vírion duas cópias de RNA de filamento único que se replica pela formação de um ácido desoxirribonucléico (DNA) dependente da transcriptase reversa, o que permite a integração viral ao genoma do hospedeiro. Ovírus apresenta tropismo principalmente pelas células do sistema monocíticofagocitário que funcionam como meio de distribuição e replicação viral. "A replicação restrita" permite que o vírus permaneça latente nos monócitos do hospedeiro e não seja detectável pelo sistema imune ( $\mathrm{PuGH}$, 2004). A replicação viral geralmente é limitada por determinados fatores, entre os quais destaca-se a restrição da replicação viral mediada por interferon, produzido por linfócitos ativados durante sua interação com os macrófagos infectados. Contudo, é o tropismo do vírus por células do sistema imune, particularmente monócitos e macrófagos, o principal fator responsável pela habilidade dos lentivírus em causar infecções crônicas, que persistem por toda a vida do animal (PINHeIro, 2001).

Embora geralmente assintomática, a infecção pelo CAEV pode causar patologias multissistêmicas de evolução geralmente crônicas, com agravamento progressivo das lesões, perda de peso e debilidade até a morte (CAllado et al., 2001). A viremia observada na infecção está associada à disseminação viral realizada célula a célula, sendo a principal fonte de transferência dentro do hospedeiro (Pinheiro, 2001).

A manifestação da CAEem reprodutores ematrizes de alto valor genético tem acarretado grandes problemas sanitários, pois, além da transmissão horizontal, o vírus pode estar presente no sêmen de animais infectados (WhathaLL, 1995). Assim, as medidas para controlar a doença, como o sacrifício destes animais, representam grande prejuízo econômico e genético, tanto na perda do indivíduo quanto do potencial dos seus descendentes. Entretanto, foi observadoqueouso de tecnologias reprodutivas podem ser utilizadas na obtenção decrias livres oriundas de pais portadores do CAEV (PINHeIRO etal., 2005; Al-Qudah etal.,2006). Entre estas tecnologias, destacam-se a colheita e transferência de embriões de cabras infectadas e a seleção de amostras de sêmen livres do vírus pelanested polymerase chain reaction, visto que ainda não foram desenvolvidos protocolos de tratamento que eliminem o CAEV do sêmen (ANDRIOLI, 2001).

Como o desenvolvimento da CAE tem caráter insidioso, progredindo lentamente por meses ou anos, estes reprodutores poderiam ser preservados para reprodução, desde que previamente fixado o período da eliminação destes do rebanho e seguidos todos os cuidados sanitários para impedir a transmissão horizontal do vírus. Além disso, é importante que os animais estejam em condições clínicas adequadas, não manifestem sinais de sofrimento e que os parâmetros de fertilidade permaneçam normais, considerando também o estresse térmico ao qual estão submetidos no Nordeste do Brasil.

Ademais, a avaliação da viabilidade da manutenção destes animais é dificultada pela escassez de dados acerca de parâmetros clínicos e hematológicos de bodes naturalmente infectados pelo vírus da CAE, bem como a influência da estação do ano sobre estes. Desse modo, o objetivo deste trabalho foi avaliar os parâmetros clínicos e hematológicos de reprodutores infectados naturalmente pelo vírus da CAE, bem como verificar a influência da transição das estações seca e chuvosa no Ceará sobre eles.

\section{MATERIAL E MÉTODOS}

\section{Período de execução e dados climáticos}

O experimento foi realizado no período de setembro de 2006 a fevereiro de 2007. Neste trabalho, os meses de setembro e outubro de 2006 foram considerados como pertencendo à estação seca, o período de transição foi compreendido pelos meses denovembro 
e dezembro de 2006 verificado pelo aumento da umidade relativa do ar, proporcionando melhor conforto ambiental aos animais), enquanto a estação chuvosa foi representada pelos meses de janeiro e fevereiro de 2007. Durante o experimento foram observados os dados de precipitação $\left(\mathrm{mm}^{3}\right)$ (Fig. 1), temperatura média $\left({ }^{\circ} \mathrm{C}\right)$ (Fig. 2) e umidade relativa do ar (\%) (Fig. 3). As médias mensais dos parâmetros climáticos foram obtidas com a unidade meteorológica local da Empresa Brasileira de Pesquisa Agropecuária - Embrapa Caprinos.

\section{Localização e seleção dos animais}

O experimento foi conduzido na Empresa Brasileira de Pesquisa Agropecuária -Embrapa Caprinos, localizada no Município de Sobral, na região norte do Estado do Ceará (latitude $3^{\circ} 45^{\prime} 0,5^{\prime \prime}$ sul, longitude $40^{\circ} 20^{\prime} 45,8^{\prime \prime}$ oeste, 111 metros de altitude). Foram selecionados oito reprodutores naturalmente infectados pelo CAEV após comprovação de, no mínimo, dois testes de imunodifusão em gel deágar (IDGA) positivos com intervalos de 60 dias e um resultado positivo pela nested polymerase chain reaction (Nested-PCR) no sangue. Os animais pertenciam ao rebanho experimental da Empresa Brasileira de Pesquisa Agropecuária - Embrapa Caprinos, sendo três reprodutores da raça Saanen e cinco da raça Anglo Nubiana, apresentando idades entre 3 a 4 anos e peso médio de $43,87 \mathrm{~kg}$. Os machos caprinos foram alojados em baias e mantidos em um sistema semi-intensivo de criação, com área de lazer isolada por cerca dupla, recebendo ração balanceada, sal mineral, volumoso no coxo e água ad libitum.

Este trabalhofoi oriundo do projeto $\mathrm{MP} 3 \mathrm{~N}^{\circ} 032535$, o qual está de acordo com os princípios éticos na experimentação animal, adotados pelo Colégio Brasileiro de Experimentação Animal (COBEA). Durante todo o período experimental, os animais foram avaliados por junta de médicos veterinários, a acomodação e tratamento dispensado aos animais experimentais foram realizados deforma humanitáriae, quando necessário, foi estabelecida terapêutica medicamentosa com a finalidade de evitar qualquer tipo de sofrimento.

\section{Avaliação dos parâmetros clínicos}

Quinzenalmente, os animais foram submetidos a exameclínico no qual foram verificadas a presença de movimentos ruminais, auscultação pulmonar, coloração das mucosas orais e oculares, e palpados os linfonodos superficiais (PuGH, 2004). Os parâmetros de freqüência cardíaca (bpm) e freqüência respiratória (mpm) foram avaliados com auxílio de estetoscópio, enquanto a temperatura retal $\left({ }^{\circ} \mathrm{C}\right)$ foi aferida com termômetro clínico. Por ocasião do exame clínico, os animais tiveram o peso corporal $(\mathrm{kg})$ mensurado e o escore corporal (0-5) avaliado segundo a metodologia descrita por Ribeiro (1997). Os animais foram ainda submetidos à avaliação articular constituída pela observação de claudicação e dor e cálculo do índice articular clínico (IAC), segundo PINHEIRO et al. (2005).

\section{Avaliação dos parâmetros hematológicos}

O sangue dos animais experimentais foi coletado mensalmente por venipunção da jugular e avaliados os seguintes parâmetros hematológicos: contagem de hemáciasemcâmarashematrimétricas (milhões $/ \mu \mathrm{L}$ ), microhematócrito (\%), hemoglobina pelo método da cianometahemoglobina (g/dL), VCM (fL), $\mathrm{HCM}(\mathrm{pg})$, CHCM (\%), assim como contagem de leucócitos em câmaras hematrimétricas (milhares/ $\mu \mathrm{L}$ ) e contagem diferencial de leucócitos em esfregaços corados por panótico rápido, os quais foram classificados como metamielócitos $(/ \mu \mathrm{L})$, neutrófilos bastonetes $(/ \mu \mathrm{L})$, neutrófilos segmentados $(/ \mu \mathrm{L})$, eosinófilos $(/ \mu \mathrm{L})$, basófilos $(/ \mu \mathrm{L})$, linfócitos $(/ \mu \mathrm{L})$ e monócitos $(/ \mu \mathrm{L})$ (Pugh, 2004).

\section{Análise estatística}

Os dados foram expressos na forma de média e erro padrão e analisados pelo teste $t$ deStudent, exceto para o escore corporal e os valores do leucograma nos quais foi utilizado o teste de Kruskal Wallis utilizando o software Staview 5.0 (SAS, 2001). As diferenças foram consideradas estatisticamente significativas quando $\mathrm{P}<0,05$.

\section{RESULTADOS E DISCUSSÃO}

Os dados referentes às condições climáticas durante o experimento estão apresentados nas Figuras 1 a 3. A partir do mês de janeiro foi observado um aumento da precipitação com conseqüente decréscimo na temperatura em fevereiro. A umidade relativa do ar alcançou o valor máximo no mês de fevereiro, quando também foi observado um valor máximo de precipitação, condições que caracterizam o início da estação chuvosa.

Os animais experimentais apresentaram condição corporal média (peso e o escore) estável durante todo o período de avaliação, não diferindo, estatisticamente entre as estações climáticas (Tabela 1), revelando que os animais apresentaram boa adaptação a alimentação oferecida, e adequado planejamento nutricional, não sofrendo influência da estação cli- 
mática. Neste trabalho, os animais não apresentaram alteração significativa do peso e escore corporal em relação à média do grupo ou individual, contudo revelaram condição corporal abaixo do desejável e metade destes apresentaram algum grau de redução no peso e escore corporal o que poderia ser atribuída tanto à condição clínica de emagrecimento crônico provocada pela CAE (FRANKE, 1998), quanto ao parasitismo gastrintestinal (SILVA, 1996).

Osvalores deIAC apresentados pelos reprodutores não sofreram influência da estação climática, sendo os animais clinicamente considerados suspeitos de artrite segundo FRANKE (1998). Entretanto, três reprodutores apresentaram IAC igual ou superior a 7 durante o período de avaliação, porém sem apresentar evidentes manifestações de dor ou claudicação. Estes três animais apresentaram ainda alguma outra alteração da condição clínica concomitante ao aumento do IAC em algum momento do período de avaliação, como hipocromia de mucosas. Simultaneamente, um destes apresentou corrimento nasal no período de transição entre as estações, sendo submetido à terapia antibiótica com remissão do sinal clínico, e alteração da ausculta pulmonar (som úmido), sugestiva da presença de pneumonia, na estação chuvosa (CALLADO et al., 2001).

Apenas um reprodutor apresentou alteração estatisticamente significativa do IAC, em que foi observada uma redução significativa do parâmetro aferidona estação chuvosa quando comparado à estação seca

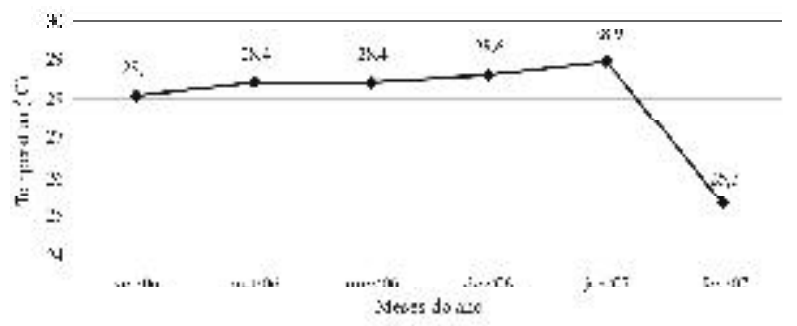

Fig. 2 - Temperatura média $\left({ }^{\circ} \mathrm{C}\right)$ durante os meses de setembro de 2006 a fevereiro de 2007 no Município de Sobral, CE.
(Tabela 2). Durante o experimento outro reprodutor caprino apresentou claudicação de uma das patas, observada no final da estação chuvosa, quando o animal apresentava um IAC de $6,0 \mathrm{~cm}$. Esse mesmo animal apresentou alteração na ausculta pulmonar no mês anterior, sugestivo da presença de pneumonia.

A artrite é um achado comum em animais infectados pelo vírus da CAE, embora entre as principais apresentações clínicas sejam observadas ainda a pneumonia intersticial e a perda de peso progressiva em caprinos adultos (AL-QUDAH etal., 2006; FRANKE, 1998). Outros autores descreveram a pneumonia intersticial como um sinal subclínico habitualmente observado em caprinos infectados em qualquer idade, deste modo a doença respiratória crônica poderia ser o sinal mais freqüente na maioria dos casos (DAWSON; WILESMITH, 1985).

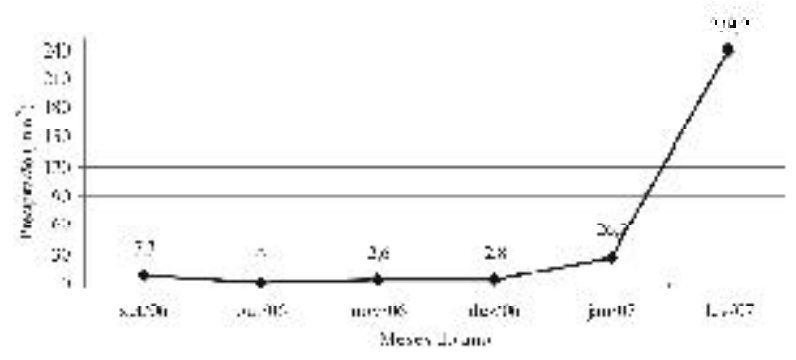

Fig. 1 - Precipitação média $\left(\mathrm{mm}^{3}\right)$ durante os meses de setembro de 2006 a fevereiro de 2007 no Município de Sobral, CE.

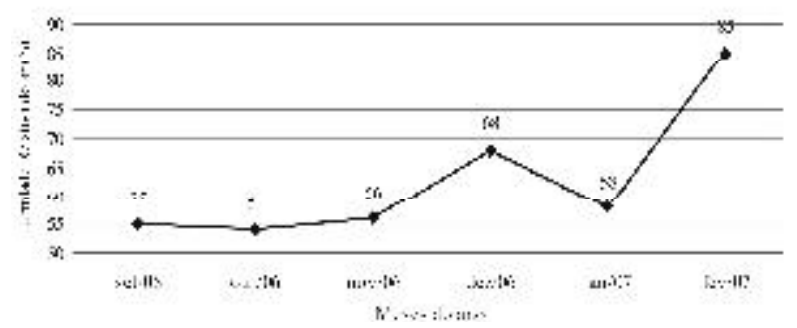

Fig. 3-Umidade relativa do ar (\%) média durante os meses de setembro de 2006 a fevereiro de 2007 no Município de Sobral, CE.

Tabela 1 - Parâmetros clínicos (média \pm ep) de bodes naturalmente infectados pelo vírus da artrite encefalite caprina durante a transição da estação seca para a chuvosa*.

\begin{tabular}{lcrr}
\hline Parâmetro & Estação seca & Período de transição & Estação chuvosa \\
\hline Freqüência Cardíaca (bpm) & $80,69 \pm 4,28 \mathrm{ab}$ & $81,13 \pm 2,52 \mathrm{a}$ & $90,09 \pm 2,87 \mathrm{~b}$ \\
Freqüência Respiratória $(\mathrm{mpm})$ & $35,45 \pm 2,81 \mathrm{a}$ & $34,06 \pm 3,06 \mathrm{a}$ & $36,81 \pm 3,33 \mathrm{a}$ \\
Temperatura Retal $\left({ }^{\circ} \mathrm{C}\right)$ & $38,89 \pm 0,20 \mathrm{a}$ & $38,33 \pm 0,13 \mathrm{~b}$ & $39,15 \pm 0,09 \mathrm{a}$ \\
Índice Articular Clínico $(\mathrm{cm})$ & $6,32 \pm 0,11 \mathrm{a}$ & $6,27 \pm 0,12 \mathrm{a}$ & $6,30 \pm 0,13 \mathrm{a}$ \\
Peso $(\mathrm{kg})$ & $51,66 \pm 3,64 \mathrm{a}$ & $46,86 \pm 3,71 \mathrm{a}$ & $42,91 \pm 3,61 \mathrm{a}$ \\
Escore corporal $(1-5)$ & $2,54 \pm 0,13 \mathrm{a}$ & $2,69 \pm 0,14 \mathrm{a}$ & $2,31 \pm 0,12 \mathrm{a}$ \\
\hline
\end{tabular}

*Letras diferentes na mesma linha diferem significativamente $(\mathrm{P}<0,05)$. 
Tabela 2-Índice articular clínico individual (média \pm ep) de bodes naturalmente infectados pelo vírus da artrite encefalite caprina durante a transição da estação seca para a chuvosa*.

\begin{tabular}{clccc}
\hline No do brinco & Raça & Estação seca & Período de transição & Estação chuvosa \\
\hline 17 & Saanen & $6,13 \pm 0,13 \mathrm{a}$ & $5,75 \pm 0,14 \mathrm{ab}$ & $5,50 \pm 0,00 \mathrm{~b}$ \\
45 & Anglo Nubiana & $6,88 \pm 0,38 \mathrm{a}$ & $6,88 \pm 0,13 \mathrm{a}$ & $7,00 \pm 0,20 \mathrm{a}$ \\
283 & Anglo Nubiana & $5,88 \pm 0,13 \mathrm{a}$ & $5,75 \pm 0,14 \mathrm{a}$ & $6,13 \pm 0,13 \mathrm{a}$ \\
296 & Saanen & $5,50 \pm 0,00 \mathrm{a}$ & $5,38 \pm 0,13 \mathrm{a}$ & $5,50 \pm 0,00 \mathrm{a}$ \\
1317 & Anglo Nubiana & $6,08 \pm 0,08 \mathrm{a}$ & $6,13 \pm 0,13 \mathrm{a}$ & $6,13 \pm 0,24 \mathrm{a}$ \\
1318 & Anglo Nubiana & $6,50 \pm 0,46 \mathrm{a}$ & $7,25 \pm 0,14 \mathrm{a}$ & $7,00 \pm 0,29 \mathrm{a}$ \\
1408 & Anglo Nubiana & $6,88 \pm 0,32 \mathrm{a}$ & $6,75 \pm 0,25 \mathrm{a}$ & $7,00 \pm 0,35 \mathrm{a}$ \\
3580 & Saanen & $6,13 \pm 0,13 \mathrm{a}$ & $6,25 \pm 0,14 \mathrm{a}$ & $6,13 \pm 0,13 \mathrm{a}$ \\
\hline
\end{tabular}

${ }^{*}$ Letras diferentes na mesma linha diferem significativamente $(\mathrm{P}<0,05)$.

Tabela 3 - Parâmetros hematológicos (média \pm ep) de bodes naturalmente infectados pelo vírus da artrite encefalite caprina durante a transição da estação seca para a chuvosa*.

\begin{tabular}{lccr}
\hline Parâmetro & Estação seca & Período de transição & Estação chuvosa \\
\hline Hemácias (milhões $/ \mu \mathrm{L})$ & $971,80 \pm 88,31 \mathrm{a}$ & $840,88 \pm 76,22 \mathrm{a}$ & $863,44 \pm 73,36 \mathrm{a}$ \\
$\mathrm{Ht}(\%)$ & $24,00 \pm 1,06 \mathrm{a}$ & $21,88 \pm 1,17 \mathrm{a}$ & $21,63 \pm 1,36 \mathrm{a}$ \\
$\mathrm{Hb}(\mathrm{g} / \mathrm{dL})$ & $7,85 \pm 0,33 \mathrm{a}$ & $6,92 \pm 0,33 \mathrm{a}$ & $7,44 \pm 0,38 \mathrm{a}$ \\
$\mathrm{VCM}(\mathrm{fL})$ & $23,49 \pm 0,83 \mathrm{a}$ & $25,13 \pm 1,29 \mathrm{a}$ & $26,66 \pm 1,62 \mathrm{a}$ \\
$\mathrm{HCM}(\mathrm{pg})$ & $7,65 \pm 0,26 \mathrm{a}$ & $5,41 \pm 0,78 \mathrm{~b}$ & $9,28 \pm 0,63 \mathrm{c}$ \\
$\mathrm{CHCM}(\%)$ & $32,79 \pm 0,66 \mathrm{ab}$ & $31,78 \pm 0,70 \mathrm{a}$ & $34,94 \pm 1,07 \mathrm{~b}$ \\
Leucócitos $\left(\right.$ milhares $\left./ \mathrm{mm}^{3}\right)$ & $9363,33 \pm 1020,89 \mathrm{a}$ & $8603,50 \pm 1030,32 \mathrm{a}$ & $10962,50 \pm 930,31 \mathrm{a}$ \\
Neutrófilos bastonetes $(/ \mu \mathrm{L})$ & $90,47 \pm 24,75 \mathrm{a}$ & $168,75 \pm 127,20 \mathrm{a}$ & $55,53 \pm 24,24 \mathrm{a}$ \\
Neutrófilos segmentados $(/ \mu \mathrm{L})$ & $5045,77 \pm 597,96 \mathrm{a}$ & $5120,06 \pm 770,88 \mathrm{a}$ & $6437,28 \pm 659,34 \mathrm{a}$ \\
Eosinófilos $(/ \mu \mathrm{L})$ & $437,60 \pm 129,66 \mathrm{a}$ & $535,75 \pm 107,28 \mathrm{a}$ & $1017,34 \pm 173,19 \mathrm{~b}$ \\
Basófilos $(/ \mu \mathrm{L})$ & $22,50 \pm 12,07 \mathrm{a}$ & $30,75 \pm 14,85 \mathrm{a}$ & $0,0 \pm 0,0 \mathrm{a}$ \\
Linfócitos $(/ \mu \mathrm{L})$ & $3730,53 \pm 467,14 \mathrm{a}$ & $2709,78 \pm 325,51 \mathrm{a}$ & $3351,44 \pm 335,58 \mathrm{a}$ \\
Monócitos $(/ \mu \mathrm{L})$ & $36,47 \pm 17,44 \mathrm{a}$ & $38,41 \pm 15,76 \mathrm{a}$ & $100,91 \pm 21,12 \mathrm{~b}$ \\
\hline
\end{tabular}

*Letras diferentes na mesma linha diferem significativamente $(\mathrm{P}<0,05)$.

A freqüência cardíaca foi significativamente superior na estação chuvosa em comparação ao período de transição, enquanto a temperatura retal foi significativamente superior no período de transição(Tabela 1). A variação encontrada no parâmetro freqüência cardíaca pode ser oriunda da anemia verificada nos reprodutores infectados pelo CAEV durante o período de execução do experimento. Todavia, os valores de batimentos cardíacos por minuto mantiveram-se dentro da faixa de normalidade da espécie durante todo o experimento (PugH, 2004) em concordância com as observações de PinheIro; Alves (2000), em experimento conduzido com cabras infectadas pelo CAEV apresentado a forma artrítica da doença.

Ao exame clínico os animais apresentaram movimentos ruminais a parentemente normais a auscultação durante todo o período de avaliação. Do mesmo modo, apresentaram linfonodos normais à palpação, exceto um reprodutor que apresentou discreto aumento unilateral do linfonodo pré-crural somente em um dos exames do período de transição entre as estações.

As mucosas dos reprodutores foraminspecionadas ao exame clínico, sendo observada a presença de mucosas hipocoradas em três reprodutores na estação seca, em seis animais no período de transição e em cinco na estação chuvosa. Na avaliação do sistema respiratório, além do animal que apresentou alteração no período de transição e foi tratado, anteriormente comentado, outros três reprodutores apresentaram sons anormais na ausculta da região pulmonar caracterizado por som úmido, sugestivo da presença de pneumonia, segundo CALlADOetal.(2001). Entre estes quatro animais que apresentaram alteração na ausculta pulmonar, dois apresentaram freqüência respiratória igual ou superior a $50 \mathrm{mpm}$ e os restantes apresentaram os demais parâmetros clínicos normais. SegundoPugh(2004), na pneumonia progressiva ovina, causada pelo vírus MAEDI-VISNA, os ovinos mantêm oapetite e temperatura normais embora 
possam apresentar taquipnéia. $\mathrm{Na} \mathrm{CAE}$, os animais podem apresentar tosse crônica profunda produtiva nos estágios iniciais e nos estágios finais, taquipnéia, dispnéia e ruídos pulmonares anormais. $\mathrm{O}$ aumento dos linfonodos locais pode contribuir para o aparecimento de estridor, disfagia e timpanismo(PugH,2004).

Em relação ao eritrograma, não foi observada influência da estação sobre a contagem de hemácias, hematócrito, hemoglobina e VCM (Tabela 3). Contudo, a contagem de hemácias apresentou-se inferior e o VCM superior ao considerado normal para a espécie caprina durante todo o período de avaliação segundo Garcia-Navarro; Pachaly (1994). Do mesmo modo, no período de transição e na estação seca, o hematócrito esteve abaixo dos valores normais para caprinos, contudo não foi observada influência da estação climática. OHCM variou significativamente em todas as estações climáticas observadas, apresentando valores acima da faixa normal nas estações seca echuvosa e valores inferiores ao normal para a espécie no período de transição (Pugh, 2004).

A contagem de leucócitos, neutrófilos bastonetes, neutrófilos segmentados e linfócitos apresentaramse dentro da faixa de normalidade para a espécie (JAIN, 1993) e não sofreram influência da estação climática (Tabela 3). Os números de eosinófilos, basófilos e monócitos foram estatisticamente superiores na estação chuvosa. Entretanto, os valores destas células estiveram dentro da faixa de normalidade para caprinos, exceto para os eosinófilos quando os valores aferidos durante a estação seca estiveram elevados em relação ao normal para a espécie (Tabela 3).

Durante o período de avaliação, os animais apresentaram valores no eritrograma abaixo da faixa de normalidade para caprinos _estando de acordo como achado de mucosas hipocoradas ao exame clínico, sendo indicativo de anemia verificada em reprodutores infectados pelo CAEV CRAWFORD; AdAms, 1981; PNheiro; Alves, 2000), associado ao parasitismo gastrintestinal, contudo só foram observados indícios de parasitismo, elevada contagem de ovos de parasitos por grama de fezes (OPG), bem como valores na contagem de eosinófilos superiores a faixa de normalidade na estação chuvosa.

Em relação ao aumento do HCM, a presença de reticulócitos (eritrócitos imaturos) no sangue periférico sugere a tentativa de reposição de hemácias durante um curto espaço de tempo, assim como a elevação do CHCM pode ser devida à perda de hemácias associada a anemia (GARCIA-NAVARRO; PACHALY, 1994).

Durante o processo inflamatório, os monócitos migram para o sítio problema juntamente com os linfócitos, atuando como macrófagos, a fim defagocitar partículas como microrganismos, células necrosadas e neutrófilos mortos pela ação de suas próprias enzimas ou pelo CAEV. Durante todo o experimento não foi verificada monocitose, muito provavelmente pela migração constante destes para os focos de infecção da CAE. Porém, existe descrição de monocitose associada a doenças de natureza crônica e de longa duração, como por exemplo CAE, tuberculose e brucelose (GArcia-Navarro; PACHALY, 1994).

Geralmente, os eosinófilos estão ausentes na fase aguda da doença, reaparecendo com a evolução do processo. A eosinofilia verificada durante a estação chuvosa pode-se dever ao reaparecimento destas células no término da fase aguda da inflamação, ou ainda devido a infecções parasitárias, principalmente naquelas em que há lesão tecidual, como nas parasitoses intestinais que foram verificadas com maior intensidade na estação chuvosa GARCIANavarro; Pachaly, 1994).

\section{CONCLUSÕES}

A estação climática não altera os parâmetros físicos de reprodutores caprinos infectados pelo CAEV explorados na região norte do Estado do Ceará. Todavia, a estação chuvosa propicia condições climáticas e ambientais que alteram a contagem de monócitos e eosinófilos desses reprodutores.

Machos caprinos de alto valor zootécnico e econômico, infectados naturalmente pelo $\mathrm{CAEV}$, podem apresentar condições clínicas condizentes com um possível aproveitamento para a reprodução, contudo necessitam de constante observação e atenção veterinária, para pronto atendimento e utilização de medicação de suporte, a fim de evitar o desenvolvimento de restrições clínicas decorrentes da enfermidade.

\section{AGRADECIMENTOS}

À Fundação Cearense de Apoio ao Desenvolvimento Científico e Tecnológico - FUNCAPeao Banco do Nordeste - BNB pelo apoio financeiro; e a Empresa Brasileira de Pesquisa Agropecuária - Embrapa Caprinos pela estrutura e apoio técnico.

\section{REFERÊNCIAS}

AL-QUDAH, K.; AL-MAJALI, A.M.; ISMAIL, Z.B. Epidemiological studies on caprine arthritisencephalitis virus infection in Jordan. Small Ruminant Research, v.66, p.181-186, 2006.

ANDRIOLI, A. Vírus da artrite encefalite caprina: PCR e isolamento em amostras de sêmen, fluido uterino e embriōes. 2001. 68f. Tese (Doutorado em Ciência Animal - Área de Medicina Veterinária Preventiva e Epidemiologia) - Universidade Federal de Minas Gerais, Belo Horizonte, 2001. 
CALLADO, A.K.C.; CASTRO, R.S.; TEIXEIRA, M.F.S. Lentivírus de pequenos ruminantes (CAEV e Maedivisna): revisão e perspectivas. Pesquisa Veterinaria Brasileira, v.21, p.87-97, 2001.

CRAWFORD, T.B.; ADAMS, D.S. Caprine arthritisencephalitis: clinical features and presence of antibody in selected goat populations. Journal of the American Veterinary Medical Association, v.178, p.713, 1981.

DAWSON, M.; WILESMITH, J.W. Serological survey of lentivirus (maedi visna/caprine arthritisencephalitis) infection in British goat herds. Veterinary Record, v.117, p.86-89; 1985.

FRANKE, C.R. Controle Sanitário da Artrite-Encefalite Caprina. Salvador: EDUFBA, 1998. 70p.

GARCIA-NAVARRO, C.E.K.; PACHALY, J.R. Manual de hematologia veterinária. São Paulo: Varela, 1994. 169p.

JAIN, N.C. Essentials of veterinary hematology. Philadelphia: Lea \& Febiger, 1993. 417p.

PINHEIRO, R.R.; ALVES, F.S.F. Valores dos parâmetros clínicos, líquido sinovial e hemogramas de cabras com artrite encefalite caprina viral. Revista Brasileira de Medicina Veterinária, v.20, n.6, p.263-264, 2000.

PINHEIRO, R.R. Vírus da artrite encefalite caprina: desenvolvimento e padronização de ensaios imunoenzimáticos (ELISA e Dot-Blot) e estudo epidemiológico no Estado do
Ceará. 2001. 115f. Tese (Doutorado em Ciência Animal - Área de Medicina Veterinária Preventiva e Epidemiologia) - Universidade Federal de Minas Gerais, Belo Horizonte, 2001.

PINHEIRO, R.R.; GOUVEIA, A.M.G.; ALVES, F.S.F.; ANDRIOLI, A. Medidas carpo-metacarpianas como índice articular clínico em caprinos. Revista Brasileira de Medicina Veterinária, v.27, n.4, p.170-173, 2005.

PUGH, D.G. Clínica de ovinos e caprinos. São Paulo: Roca, 2004. 513p.

RIBEIRO, S.D.A. Caprinocultura: criação racional de caprinos. São Paulo: Nobel, 1997. 318p.

SAS. SAS user's guide statistic. SAS Inst., Inc., Cary, NC., 2001.

SILVA, R.R. Sistema agroindustrial da caprinocultura leiteira no Brasil. 1996. 38f. Trabalho de Graduação (Monografia, Especialização em Agribusiness) Universidade Federal da Paraiba, Campina Grande, 1996.

WHATHALL, A.E. Embryo transfer and disease transmission in livestock a review of recent research. Theriogenology, v.43, p.81-88, 1995.

Recebido em 12/8/07

Aceito em 20/5/08 